\title{
p21-Activated Kinase-1 Promotes Aggressive Phenotype, Cell Proliferation, and Invasion in Gestational Trophoblastic Disease
}

\author{
Michelle K.Y. Siu, ${ }^{*}$ Matthew C.W. Yeung, ${ }^{*}$ \\ HuiJuan Zhang, ${ }^{*}$ Daniel S.H. Kong, ${ }^{*}$ \\ Joanna W.K. Ho, ${ }^{*}$ Hextan Y.S. Ngan, ${ }^{\dagger}$ \\ Dominic C.W. Chan, ${ }^{*}$ and Annie N.Y. Cheung ${ }^{*}$ \\ From the Departments of Patbology, and Obstetrics and \\ Gynecology, ${ }^{\dagger}$ University of Hong Kong, Hong Kong, SAR China
}

Gestational trophoblastic disease (GTD) includes hydatidiform mole (HM), which can develop persistent gestational trophoblastic neoplasia requiring chemotherapy; choriocarcinoma, which is a frankly malignant tumor; placental site trophoblastic tumor; and epithelioid trophoblastic tumor. p21-Activated kinases (PAKs) promote malignant tumor progression. Therefore, this study investigated PAK1, PAK2, and p-PAK2 $\operatorname{Ser}^{20}$ in the pathogenesis of GTD. By real-time PCR, PAK1 mRNA was significantly higher in HMs, particularly metastatic HMs $(P=0.046)$ and HMs that developed persistent disease $(P=0.011)$, when compared with normal placentas. By immunohistochemistry, significantly increased cytoplasmic PAK1 immunoreactivity in cytotrophoblasts was also detected in HMs $(P=0.042)$ and choriocarcinomas $(P=$ 0.003). In addition, HMs that developed persistent disease displayed higher PAK1 immunoreactivity than those that regressed $(P=0.016)$, and elevated PAK1 immunoreactivity was observed in placental site trophoblastic tumors. Indeed, there was significant positive correlation between PAK1 expression and the proliferative indices $\mathrm{Ki}-67(P=0.016)$ and MCM7 $(P=0.026)$. Moreover, higher PAK1 mRNA and protein expression was confirmed in the choriocarcinoma cell-lines JEG-3 and JAR; however, PAK2 mRNA and p-PAK2 immunoreactivity showed a similar expression pattern in normal first trimester placentas and GTD. Knockdown of PAK1 in JEG-3 and JAR reduced cell proliferation, migration, and invasion ability, up-regulated p16, and down-regulated vascular endothelial growth factor and MT1-MMP expression. This is the first report revealing the involvement of PAK1 in the pathogenesis and clinical progress of GTD. (Am J Patbol 2010, 176:3015-3022; DOI: 10.2353/ajpath.2010.091263)

Gestational trophoblastic disease (GTD) is a disease of the placenta resulting from abnormal trophoblastic proliferation. It encompasses hydatidiform mole (HM), choriocarcinoma (CCA), placental site trophoblastic tumor (PSTT), and epithelioid trophoblastic tumor. The latter three are malignant tumors, whereas HMs are nonneoplastic lesions with an increased risk of malignant transformation. Furthermore, $8 \%$ to $30 \%$ of HMs may persist after suction evacuation and develop gestational trophoblastic neoplasia (GTN), hence requiring chemotherapy. Although the response of GTD to chemotherapy is in general very good, chemoresistant cases still exist despite advances in chemotherapy. While there is growing understanding in the molecular biology of GTD, the precise molecular pathways of its development should be further explored. ${ }^{1-3}$

p21-Activated kinases (PAKs) were initially discovered as effector molecules of Rho GTPases, Rac, and CDC42, ${ }^{4}$ and are increasingly recognized as important mediators for a wide variety of cellular functions, including cell morphogenesis, motility, mitosis, apoptosis, and angiogenesis. ${ }^{5,6}$ PAKs have been divided into group I (PAKs1-3) and group II (PAKs4-6), bases on structural organization and mode of regulation. ${ }^{5}$ In group I PAKs, the p21-binding domain in the $\mathrm{N}$-terminal domain binds small GTPases Rac and CDC42 to cause autophosphorylation of certain sites in the N-terminal inhibitory domain, leading to conformational change that releases the autoinhibition and activates the kinase activity. ${ }^{5}$ Phosphorylation of PAK1 at Ser ${ }^{21}$ regulates the binding of PAK1 to Nck, resulting in PAK1 cycling between membrane and

Supported by funding from the Research Grants Council of the Hong Kong Special Administrative Region (HKU 7503/06M).

M.K.Y. and M.C.W.Y. contributed equally to this work.

Accepted for publication February 16, 2010

Address reprint requests to Annie N. Y. Cheung, M.D., FRCPath, Department of Pathology, The University of Hong Kong, Queen Mary Hospital, Pokfulam Road, Hong Kong, China, E-mail: anycheun@hkucc.hku.hk. 
cytosol and finally facilitates cell migration. ${ }^{7,8}$ Its corresponding phosphorylation site at PAK2 is $\mathrm{Ser}^{20}$.

Overexpression of PAK 1 has been observed in various human cancers, ${ }^{6}$ such as breast, colorectal, and ovarian cancers. ${ }^{9}$ PAK 1 was found to regulate the invasiveness of breast cancer cells and the malignant progression of colorectal carcinomas to metastasis. ${ }^{10,11}$ PAK2 has also been found to be involved in Rac3-mediated breast cancer cell proliferation. ${ }^{12}$ The recent development of kinase inhibitors for the PAK family molecules ${ }^{13,14}$ is intriguing since they may be explored as potential therapeutic targets in chemoresistant GTD.

In this study, we investigated the expression and localization of PAK1, PAK2, and p-PAK2 $\mathrm{Ser}^{20}$ in normal human placenta and in GTD to determine whether PAK1 or PAK2 are involved in development and malignant progression of GTD. We also correlated their expression with clinical outcome and examined the in vitro effects and potential downstream targets of PAK1 on CCA cells.

\section{Materials and Methods}

\section{Selection of Clinical Samples}

Sixty-seven fresh frozen trophoblast samples were collected in Queen Mary Hospital, the University of Hong Kong including 16 first trimester placentas, 6 term placentas, 29 regressive moles (HMs that spontaneously regressed), 13 persistent moles (HMs that subsequently progressed to persistent GTN), and 3 CCAs. Among the 13 persistent moles, 6 cases developed metastasis. Forty archival paraffin blocks were also retrieved including 7 first-trimester placentas, 5 term placentas, 15 regressive moles, 8 persistent moles, and 5 CCAs. Approval was obtained from the Institutional Research Board. The gestation age of the HMs ranged from 5 weeks to 24 weeks (means 12.5 weeks). Persistent GTN was diagnosed if there was a plateau in human chorionic gonadotrophin level for 4 weeks or if there was a further increase in human chorionic gonadotrophin for three consecutive weeks when pregnancy was excluded. ${ }^{15}$ All tissue sections were reviewed using generally agreed and accepted diagnostic criteria. ${ }^{1-3}$ Most HM cases have previously been assessed by proliferation indices $\mathrm{Ki}-67^{16}$ and $\mathrm{MCM} 7^{17}$ and ploidy analysis by fluorescent microsatellite genotyping after microdissection and chromosome in situ hybridization. ${ }^{18,19}$

\section{Cell Lines}

The human CCA cell lines, JEG-3 and JAR, were obtained from American Type Culture Collection (Rockville, MD). The normal trophoblast cell line, TEV1, was previously established and characterized in our center. ${ }^{20}$ All cells were grown in Minimum Essential Medium Eagle (Sigma St. Louis, MO) supplemented with 10\% fetal bovine serum (JRH Biosciences, Lenexa, KS) and $100 \mathrm{U} / \mathrm{ml}$ penicillin and streptomycin (Invitrogen, San Diego, CA).
Table 1. Primers Used for Real-Time PCR

\begin{tabular}{|c|c|c|}
\hline Gene & $\begin{array}{l}\text { Primer } \\
\text { direction }\end{array}$ & Primer sequence \\
\hline PAK1 & $\begin{array}{l}\text { Forward } \\
\text { Reverse }\end{array}$ & $\begin{array}{l}\text { 5'-AGTTTCAGAAGATGAGGATGATGA-3' } \\
5^{\prime} \text {-AATCACAGACCGTGTGTATACAG-3' }\end{array}$ \\
\hline PAK2 & Forward & $\begin{array}{l}5^{\prime}-\text { AGAAACAGCTTGCATGGATGAA-3' } \\
5^{\prime}-\mathrm{TCTCTGTGGATCACTTGATTAGCAT-3,}\end{array}$ \\
\hline p16 & $\begin{array}{l}\text { Reverse } \\
\text { Forward } \\
\text { Reverse }\end{array}$ & $\begin{array}{l}\text { 5'-TCTCTGTGGATCACTTGATTAGCAT-3' } \\
\text { 5'-CATAGATGCCGCGGAAGGT-3' } \\
5^{\prime} \text {-GGATTAGGGCTTCCTCTTGGA - }\end{array}$ \\
\hline CDC25A & $\begin{array}{l}\text { Forward } \\
\text { Reverse }\end{array}$ & $\begin{array}{l}5^{\prime}-\text { AGATAGCAGTGAACCAGG- } 3^{\prime} \\
5^{\prime}-\text { TGCATCGGTTGTCAAGG- } 3^{\prime}\end{array}$ \\
\hline p21 & $\begin{array}{l}\text { Forward } \\
\text { Reverse }\end{array}$ & $\begin{array}{l}\text { 5'-GCAGACCAGCATGACAGATTTC-3' } \\
\text { 5'-GGATTAGGGCTTCCTCTTGGA-3' }\end{array}$ \\
\hline CYCLIN D1 & $\begin{array}{l}\text { Forward } \\
\text { Reverse }\end{array}$ & $\begin{array}{l}5^{\prime}-\text { GCTGCTCCTGGTGAACAAGC- } 3^{\prime} \\
5^{\prime}-\text { TTCAATGAAATCGTGCGGG- } 3^{\prime}\end{array}$ \\
\hline CYCLIN D2 & $\begin{array}{l}\text { Forward } \\
\text { Reverse }\end{array}$ & $\begin{array}{l}\text { 5'-TGATGGGGAAGGAGTACAAA-3' } \\
5^{\prime}-\text { TTGGAAGAAGAAGCAGGATG- }\end{array}$ \\
\hline CYCLIN B1 & $\begin{array}{l}\text { Forward } \\
\text { Reverse }\end{array}$ & $\begin{array}{l}\text { 5'-CTTGACAACGGTGAATGGAC-3' } \\
\text { 5'-TGACAGTCATGTGCTTTGTGA-3, }\end{array}$ \\
\hline PCNA & $\begin{array}{l}\text { Forward } \\
\text { Reverse }\end{array}$ & $\begin{array}{l}5^{\prime}-\text { AGGAAGCTGTTACCATAGAGA-3' } \\
5^{\prime}-\text { ACAACAGGGGTACATCTGC- } 3^{\prime}\end{array}$ \\
\hline$c-E R B-B-2$ & $\begin{array}{l}\text { Forward } \\
\text { Reverse }\end{array}$ & $5^{\prime}-$ GCACCCAAGTGTGCACCGGC-3' \\
\hline VEGF & Forward & 5'-AACCATGAACTTTCTGCTGTCTTG-3' \\
\hline MT1-MMP & Forward & $5^{\prime}-$ ACGGAGGTGATCATCATTGAGG-3' \\
\hline GAPDH & $\begin{array}{l}\text { Forward } \\
\text { Reverse }\end{array}$ & $\begin{array}{l}\text { 5'-TCCATGACAACTTTGGTATCGTG-3' } \\
5^{\prime}-\text { ACAGTCTTCTGGGTGGCAGTG-3' }\end{array}$ \\
\hline
\end{tabular}

\section{Transient Silencing of PAK1 in JEG-3 and JAR}

The siGENOME Smart-pool for PAK1 and siControl nontargeting short interfering (si)RNA pool (100 nmol/L each; Dharmacon, Lafayette, CO) was used for transfection using SilentFect (Bio-Rad Laboratories, Hercules, CA). Specific knockdown of PAK1 was determined by realtime (q)PCR and Western blot analysis at 24 hours and 48 hours after transfection respectively. Cells were plated for MTT (3-[4,5-dimethylthiazol-2-yl]-2,5-diphenyl tetrazolium bromide), migration and invasion assays 48 hours after transfection.

\section{qPCR}

Total RNA was extracted using Trizol reagent (Invitrogen). A total of $2.5 \mu \mathrm{g}$ of total RNA was used to synthesize first strand cDNA using the SuperScript Reverse Transcriptase (Invitrogen). qPCR was performed on the ABI Prism 7700 sequence detection system..$^{21,22}$ Primer sequences for each of the genes were listed in Table 1.

\section{Western Blot Analysis}

Cell lysates were prepared in lysis buffer $(0.125 \mathrm{~mol} / \mathrm{L}$ Tris, pH 6.8 at $22^{\circ} \mathrm{C}$ containing $1 \%$ NP-40 (v/v), 2 mmol/L EDTA, $2 \mathrm{mmol} / \mathrm{L} \mathrm{N}$-ethylmaleimide, $2 \mathrm{mmol} / \mathrm{L}$ phenylmethylsulfonyl fluoride, $1 \mathrm{mmol} / \mathrm{L}$ sodium orthovanadate, and $0.1 \mu \mathrm{mol} / \mathrm{L}$ sodium okadate). The concentration of the protein was determined by detergent compatible protein assay (Bio-Rad Laboratories, Hercules, CA). Equal amounts $(35 \mu \mathrm{g})$ of protein were resolved by SDS-polyacrylamide gel electrophoresis, transferred electrophoretically onto polyvinylidene difluoride membrane, and hybridized with corresponding antibodies. ${ }^{21,22}$ Antibodies used were listed in Table $2 .^{9}$ 
Table 2. Sources and Working Dilutions of Antibodies Used in this Study

\begin{tabular}{lcll}
\hline \multicolumn{1}{c}{ Antibodies } & Catalog \# & \multicolumn{1}{c}{ Companies } & Applications* $^{*}$ \\
\hline Rabbit anti-PAK1 & 2602 & Cell Signaling Technology, Inc. (Beverly, MA) & IHC (1:40), WB (1:1000) \\
Rabbit anti-PAK1/2 & sc-881 & Santa Cruz Biotechnology Inc. (Santa Cruz, CA) & WB (1:400) \\
Rabbit anti-p-PAK2 Ser ${ }^{20}$ & 2607 & Cell Signaling Technology, Inc. & IHC (1:50), WB (1:1000) \\
Rabbit anti MT1-MMP & M3927 & Sigma (St. Louis, MO) & WB (1:1000) \\
Goat anti-ACTIN & sc-1616 & Santa Cruz Biotechnology Inc. & WB (1:200) \\
\hline
\end{tabular}

${ }^{*} \mathrm{IHC}$, immunohistochemistry; WB, western blot analysis. ${ }^{\dagger}$ This antibody against PAK1 also cross-reacted with PAK2.

\section{Immunohistochemical Staining}

Immunohistochemical staining was performed as previously described. ${ }^{21,23}$ Briefly, $5 \mu \mathrm{m}$ formalin-fixed paraffin sections were cut, deparaffinized and stained with antibodies against PAK1 and p-PAK2 $\operatorname{Ser}^{20}$ (as listed in Table 2) using UltraVision LPValue Detection System (Lab Vision Corporation, Fremont, CA). These antibodies were known to cross-react with the corresponding target proteins in humans as indicated by the manufacturers and were used in our previous study. ${ }^{9}$ Antigen recovery was performed at $95^{\circ} \mathrm{C}$ for 10 minutes using $10 \mathrm{mmol} / \mathrm{L}$ sodium citrate buffer, pH 6.0. Negative control was prepared by replacing the primary antibody with Tris-buffered saline or pre-immune IgG serum.

\section{Assessment of Immunohistochemical Staining}

The immunostaining was assessed by two individual pathologists. Staining intensity was scored on an arbitrary scale: 0 , no immunoreactivity; 1 , weak; 2 , moderate; 3 , intense. The percentage of positive cells was graded as: 0 , negative; $1,<33 \% ; 2,33$ to $67 \% ; 3,>67 \%$. The immunoreactivity was obtained by the products of the above two parameter to give a composite "Histoscore," with a maximum score of $9 .{ }^{24}$

\section{MTT Assay}

Cell proliferation/viability was assessed by MTT assay (Sigma). ${ }^{9,22}$ Cells (2000 cells/well) were seeded in 96well plates. Ten $\mu$ l of MTT was added to each well at day 5. Plates were incubated at $37^{\circ} \mathrm{C}$ for 4 hours, followed by addition of $100 \mu$ l dimethyl sulfoxide to each well for dye extraction. Cell viability was determined by measuring the absorbance of samples at $570 \mathrm{~nm}$ with $630 \mathrm{~nm}$ as the reference wavelength.

\section{In Vitro Migration and Invasion Assays}

Migration and invasion assays were performed as previously described. ${ }^{9,22}$ Briefly, $1.25 \times 10^{5}$ cells were plated on the upper compartment of a Transwell chamber and allowed to migrate through an $8-\mu \mathrm{m}$ pore size membrane or invade through a Matrigel-coated membrane. After 24 hours (migration assays) or 48 hours (invasion assays), cells on the upper side of the membrane were removed and the migrated or invaded cells were fixed, stained, and counted.

\section{Statistical Analysis}

Statistical analyses were performed using GraphPad Prism 3.0 for Windows (GraphPad Software, San Diego, CA). Mann-Whitney test (non-parametric unpaired $t$-test) was used for continuous data. Correlation between Histoscore and proliferation indices Ki-67 and MCM7 was performed using Pearson test. $P$ value of less than 0.05 was considered as statistically significant.

\section{Results}

PAK1 Was Overexpressed in HMs, CCAs, and PSTT, and Contributed to Development of GTN Among HMs

By real-time PCR, PAK1 mRNA was significantly evaluated in $\mathrm{HMs}$ when compared with normal first-trimester $(P=0.038)$ and term placentas $(P=0.025)($ Figure $1 \mathrm{~A})$. The mRNA expression of PAK1 in patients who developed persistent GTN requiring chemotherapy was significantly higher than those that had spontaneous regression of molar pregnancy $(P=0.011)$ (Figure $1 \mathrm{~A})$. We also observed significantly higher PAK1 mRNA in the HMs that developed metastasis than those without metastasis $(P=0.046)$ (Figure 1B). Moreover, PAK1 mRNA in CCAs was significantly higher when compared with normal first trimester $(P=0.007)$, term placentas $(P=0.02)$ and $\mathrm{HMs}$ $(P=0.005)$ (Figure 1A). Increase of PAK1 mRNA and protein expression was also detected in CCA cell lines, JEG-3 and JAR, as compared with the normal trophoblast cell line, TEV-1 (Figure 1, C and D).

By immunohistochemistry, PAK1 expression was predominantly confined to the cytoplasm with occasional nuclear staining detected. The immunoreactivity was localized predominantly in cytotrophoblasts and villous intermediate trophoblasts in both normal trophoblastic and GTD tissues (Figure 2). Syncytiotrophoblasts showed negative staining and PAK1 was nearly nondetectable in term placentas (Figure 2B). In cytotrophoblasts, significantly higher PAK 1 expression was revealed in $\mathrm{HMs}(P=$ $0.042)$ and CCAs $(P=0.003)$ when compared with normal placentas (Figure 2, A, C-E, and H). Consistent with the mRNA finding, we also detected significantly higher PAK1 expression in the HMs that subsequently developed persistent GTN than the HMs that spontaneously regressed $(P=0.016)$ (Figure 2, $\mathrm{C}, \mathrm{D}$, and $\mathrm{H})$. Moreover, PAK1 expression was found to correlate with proliferation 
A

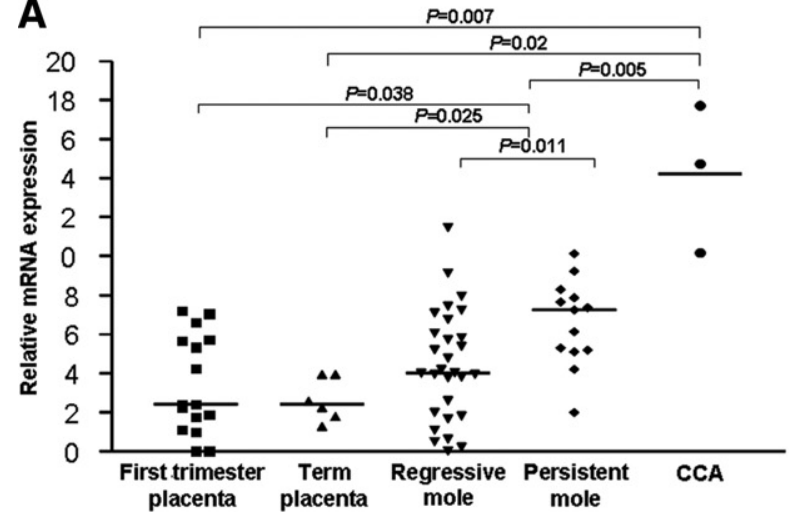

B

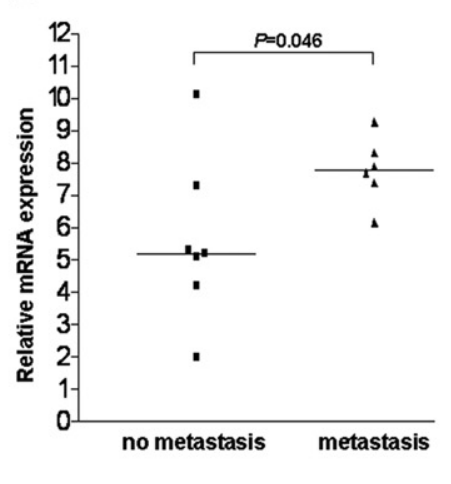

C

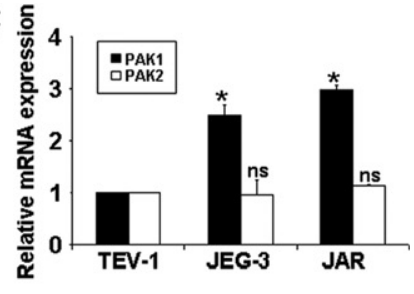

D TEV-1 JEG-3 JAR

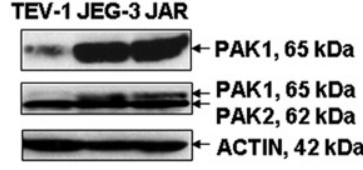

Figure 1. mRNA and protein expression of PAK1 in GTD clinical samples and cell lines. A: PAK1 mRNA profile in GTD clinical samples by qPCR. PAK1 expression was normalized with that of TBP, a housekeeping gene, and analyzed by Mann-Whitney test. B: A comparison of PAK1 mRNA expression in HMs with or without metastasis. C and D: mRNA and protein expression of PAK1 and PAK2 in a normal extravillous trophoblast cell line (TEV-1) and two CCA cell lines, JEG-3 and $\mathrm{JAR}$, as determined by qPCR (Bars $=$ means $\pm \mathrm{SD}$ of three experiments. ${ }^{*} P<0.05$ compared with TEV-1, Mann-Whitney test) and Western blot analysis respectively.

index Ki-67 (correlation coefficient $=0.453, P=0.009$, Pearson test) and MCM7 (correlation coefficient $=0.473$, $P=0.026$, Pearson test) in the group of HMs. Besides CCAs, PAK1 expression was also higher in PSTT than its normal trophoblast counterpart, extravillous implantation site intermediate trophoblast (Figure 2, F and G).

\section{No Significant Changes of PAK2 mRNA and p-PAK2 Ser ${ }^{20}$ Protein Expression Were Found in Normal First Trimester Placentas and GTD}

By real-time PCR, no significant difference in PAK2 mRNA was found between normal first trimester placentas and HMs (data not shown). PAK2 mRNA and protein expression level was also found to be similar in the normal trophoblast and CCA cell lines as detected by realtime PCR and Western blot analysis (Figure 1, C and D). By immunohistochemistry, p-PAK2 was expressed predominantly in the cytoplasm with occasional nuclear accentuation found (Figure 3). Similar level of p-PAK2 expression was detected in normal first trimester placentas, HMs and CCAs (Figure 3, A, C-E, and H). p-PAK2 was barely detectable in term placentas (Figure 3B). No significant difference in p-PAK2 expression was found between HMs that regressed and the developed GTN (Figure 3, C, D, and H). Level of p-PAK2 expression was found to be similar in PSTT $(4.50 \pm 2.45)$ and its normal trophoblast counterpart, extravillous implantation site intermediate trophoblast $(4.79 \pm 2.39)$ (Figure 3, F and G).

\section{Knockdown of PAK1 in CCA Cells Reduced Cell Proliferation and Up-Regulated p16}

To examine the functional roles of PAK 1 in CCAs cells, transient knockdown of PAK1 was performed in JEG-3 and JAR by siRNA approach. After confirming the specific knockdown of PAK1 mRNA and protein (Figure 4A), the effect on cell proliferation was first determined by MTT proliferation assay. PAK1 depleted JEG-3 and JAR cells showed significantly reduced proliferation rate when compared with control cells that transfected with control siRNA (Figure 4B). Moreover, knockdown of PAK1 in JEG-3 and JAR significantly up-regulated cell cycle inhibitor p16 mRNA expression (Figure 4D), but have no effect on other cell cycle-related genes, including CDC25A, p21, CYCLIN D1, CYCLIN D2, CYCLIN B1, proliferation cell nuclear antigen, and $c-E R B-B-2$ as evaluated by qPCR (data not shown).

\section{Transient Knockdown of PAK1 in CCA Cells Reduced Cell Migration and Invasion Ability and Down-Regulated Vascular Endothelial Growth Factor and MT1-MMP}

We next tested the effect of PAK1 depletion on cell migration and invasion by Transwell migration and invasion assays, respectively. PAK1 depleted JEG-3 and JAR cells displayed significantly reduced cell migration and invasion when compared with control cells (Figure 4C). qPCR analysis showed that reduced PAK1 expression also down-regulated mRNA expression of vascular endothelial growth factor in JEG-3 and JAR and membrane type 1-matrix metalloproteinase (MT1-MMP) in siPAK1 JEG-3 cells (Figure 4D). MT1-MMP mRNA expression was nondetectable in JAR by GPCR analysis. Western blot analysis revealed down-regulation of MT1-MMP protein expression in siPAK1 JEG-3 cells (Figure 4D).

\section{Discussion}

In this study, significantly higher PAK1 mRNA and protein expression in HMs and CCAs was detected, when compared with normal placentas. Importantly, higher PAK1 expression was associated with aggressive behavior in $\mathrm{HMs}$, as manifested by its higher expression in HMs that progressed to gestational trophoblastic neoplasia, particularly those with metastasis. Increased expression of PAK1 was also found in CCA cell lines. PSTT, the gestational trophoblastic tumor derived from extravillous im- 

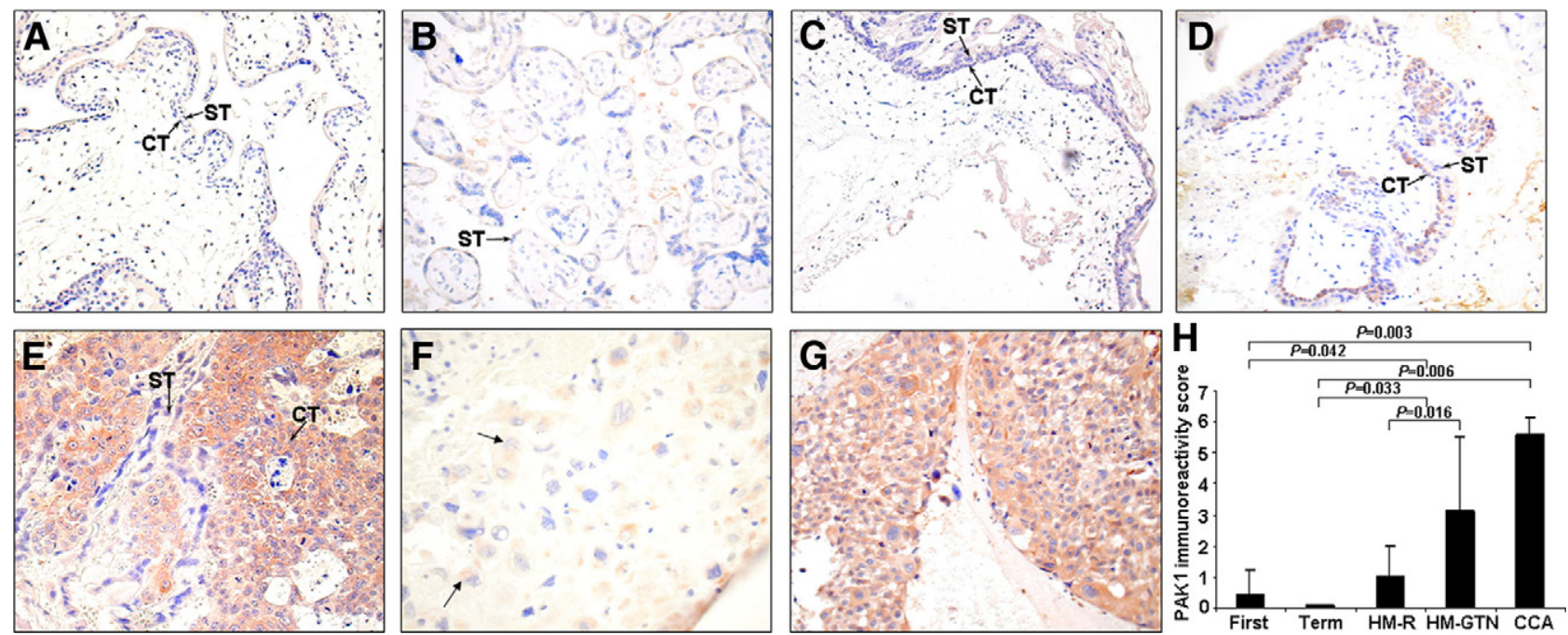

Figure 2. PAK1 immunoreactivity in first trimester placenta (A), term placenta (B), HM that regressed (C), HM that subsequently developed persistent trophoblastic neoplasia (D), CCA (E), extravillous implantation site intermediate trophoblast (F) (arrows), and PSTT (G). PAK1 immunoreactivity was mainly found in the cytoplasm of cytotrophoblast (CT) and was absent in syncytiotrophoblast (ST) (arrows). H: Bar chart showing the immunoreactivity of PAK1 in first trimester placentas (First), term placentas (Term), HM that regressed (HM-R), HM that subsequently developed persistent trophoblastic neoplasia (HM-GTN), and CCAs. The immunoreactivity of PAK1 was analyzed by Mann-Whitney test.

plantation site intermediate trophoblasts, also showed higher PAK1 expression than its normal counterpart. Our findings suggested that PAK1 may play important roles in the pathogenesis of GTD including progress of HMs into GTN with even development of metastasis as well as tumorigenesis of CCA. Indeed, overexpression and oncogenic effect of PAK1 has been earlier documented in various human malignancies, including glioblastoma, ${ }^{25}$ breast, ${ }^{26}$ colorectal, ${ }^{10}$ ovarian, ${ }^{9,27}$ and hepatocellular cancers. $^{28}$

In human placentas, cytotrophoblasts can be considered as trophoblastic stem cells responsible for proliferation, which eventually differentiate into either syncytiotrophoblasts or villous intermediate trophoblasts. ${ }^{3}$
Villous intermediate trophoblasts in turn proliferate and differentiate to implantation site and chorionic type intermediate trophoblasts. Implantation site intermediate trophoblasts infiltrate the deciduas, myometrium, and spiral arteries of the implantation site to form the maternal fetal circulation. Owning to the proliferative property of cytotrophoblast and villous intermediate trophoblast, the presence of PAK1 immunoreactivity in cytotrophoblast and villous intermediate trophoblast as demonstrated in the present study concurs with the reported proliferation enhancing function of PAK1. For instance, it was documented that constitutively active PAK1 can promote anchorage-independent growth of breast cancer cells through the mitogen-activated protein kinase pathway. ${ }^{11}$
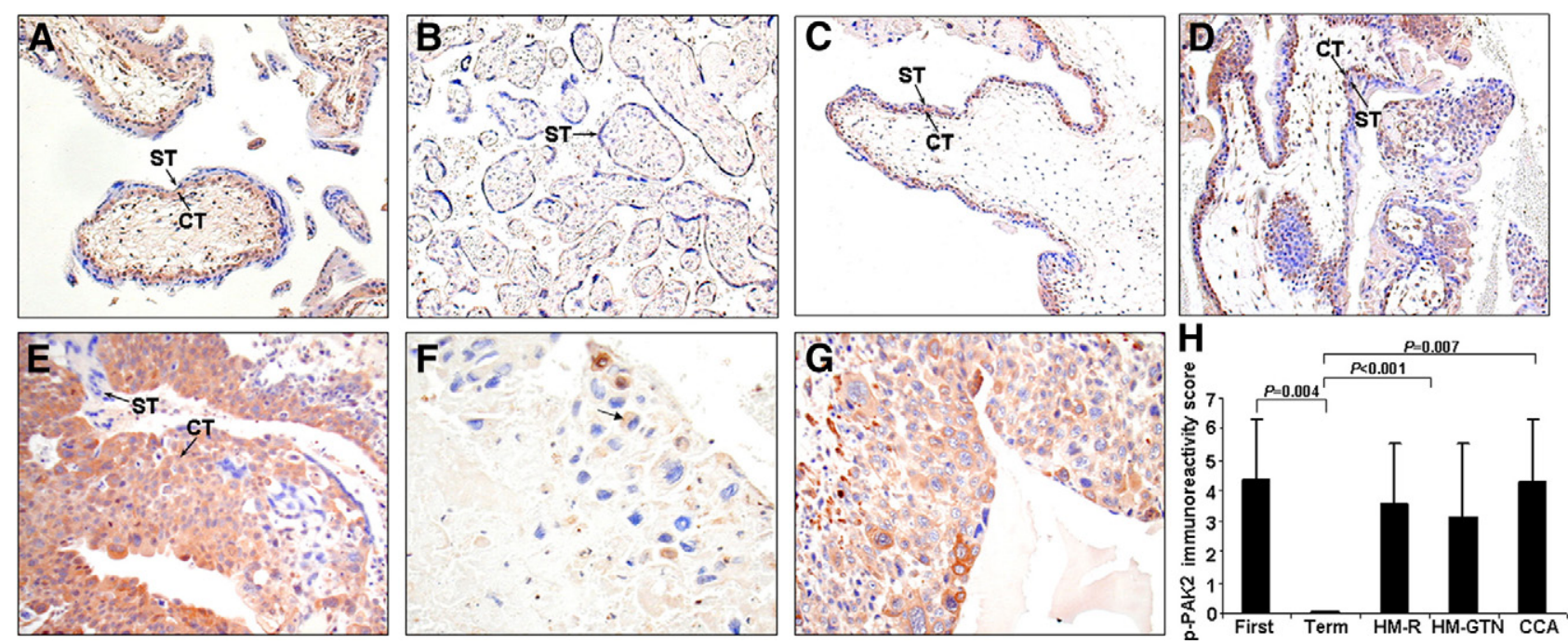

Figure 3. p-PAK2 immunoreactivity in first trimester placenta (A), term placenta (B), HM that regressed (C), HM that subsequently developed persistent trophoblastic neoplasia (D), CCA (E), extravillous implantation site intermediate trophoblast (F) (arrow), and PSTT (G). p-PAK2 immunoreactivity was mainly found in the cytoplasm of cytotrophoblast (CT) and was absent in syncytiotrophoblast (ST) (arrows). H: Bar chart showing the immunoreactivity of p-PAK2 in first trimester placentas (First), term placentas (Term), HM that regressed (HM-R), HM that subsequently developed persistent trophoblastic neoplasia (HM-GTN), and choriocarcinomas (CCAs). The immunoreactivity of p-PAK2 was analyzed by Mann-Whitney test. 
A

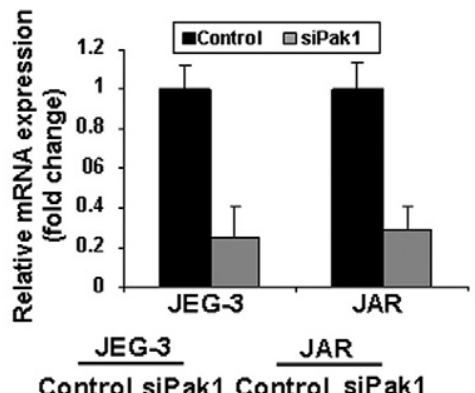

Control siPak1 Control siPak1

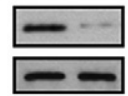

C
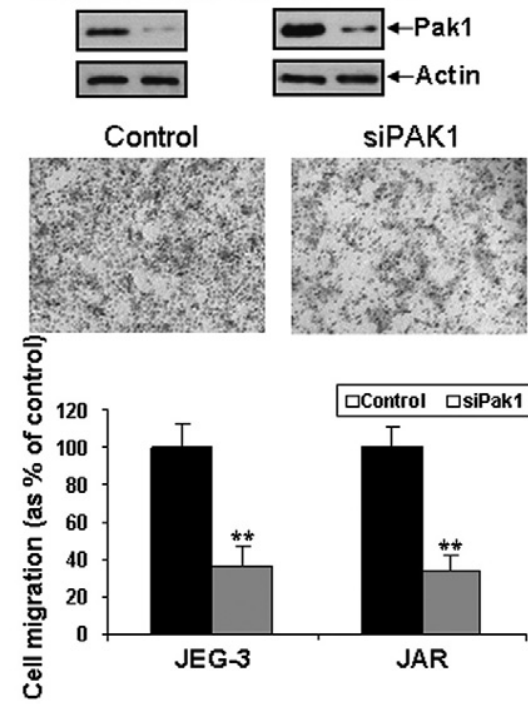

D $\overline{\mathrm{o}} 600$

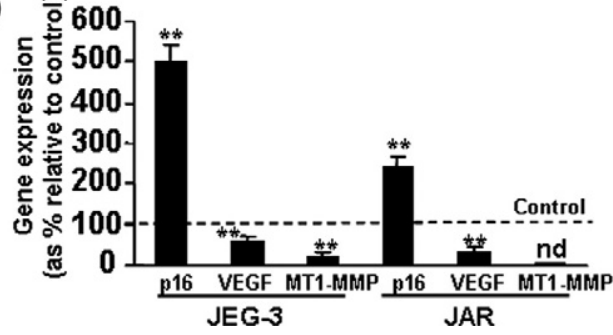

B

SiPAK1

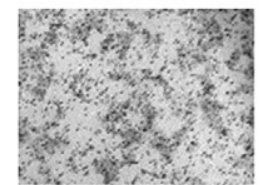

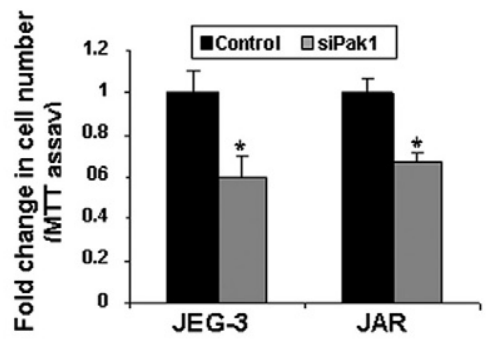

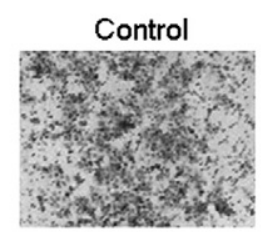

siPAK1

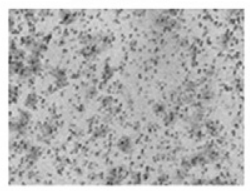

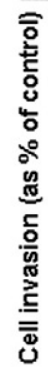

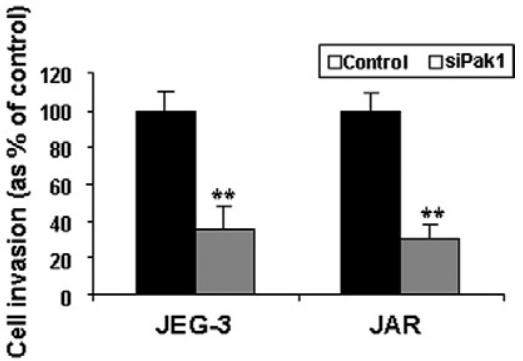

JEG-3

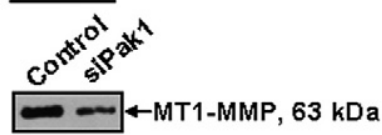

Figure 4. Transient knockdown of PAK1 impeded JEG-3 and JAR cell proliferation, migration, and invasion, up-regulated p16 and downregulated VEGF and MT1-MMP. A: Specific knockdown of PAK1 (siPAK1) mRNA and protein expression in JEG-3 and JAR cells by QPCR (upper panel) and Western blot analysis (lower panel) respectively. PAK1 mRNA expression in control was arbitrarily set as 1 . Bars $=$ means $\pm \mathrm{SD}$ of three experiments. B: Cell proliferation rate in control and siPAK1 JEG-3 and JAR as determined by MTT assay. The absorbance of control was arbitrarily set as 1 . Bars $=$ means $\pm \mathrm{SD}$ of three experiments. ${ }^{*} P<$ 0.05, Mann-Whitney test. C: In vitro migration (left panel) and invasion assays (right panel) in control and siPAK1 JEG-3 and JAR. Upper panels: representative images showing control and siPAK1 JEG-3 cells migrated or invaded to the lower chamber through the transwell membrane without or with Matrigel coating after 24 and 48 hours respectively. Lower panels: Bars = mean $\pm \mathrm{SD}$ of cell migration or invasion as percentage of control in five fields of triplicate wells from three experiments. ${ }^{* *} P<0.005$ Mann-Whitney test. D: qPCR analysis (left panel) on the mRNA levels of p16, VEGF, and MT1-MMP in control and siPAK1 JEG-3 and JAR. Bars $=$ means $\pm \mathrm{SD}$ of three experiments. ${ }^{* * *} P<$ 0.005 , Mann-Whitney test; nd, non-detectable. Western blot analysis (right panel) on MT1MMP protein expression in control and siPAK1 JEG-3.
Another study also reported that ETK tyrosine kinase can activate PAK1 and increase proliferation, anchorage-independent growth, and tumorigenicity of breast cancer cells. ${ }^{26}$ In fibroblasts, CDC2A-mediated PAK1 phosphorylation on Thr212 has been found to regulate postmitotic spreading, which is an essential step for cell cycle progression and proliferation. ${ }^{29}$ In a transgenic mouse model, overexpression of constitutively activate PAK1 can stimulate downstream proliferative signaling effectors MEK $1 / 2$ and p38- mitogen-activated protein kinase and was sufficient for mammary gland tumorigenesis. ${ }^{30}$ The present findings regarding the correlation of PAK1 expression with the proliferative indices $\mathrm{Ki}-67$ and MCM7 in $\mathrm{HMs}$ and the proliferation promoting effect of PAK1 on CCA cells as revealed using siRNA approach further support the involvement of PAK1 in trophoblasts proliferation.

We further elucidate p16 as one of the downstream targets of PAK1 in CCA cell lines, as manifested by its up-regulation in PAK1 depleted CCA cells. p16 is an inhibitor of the cyclin D-dependent kinases, CDK4 and
CDK6, which blocks S-phase entry through the disruption and inhibition of the complexes containing D-type cyclins and either CDK4 or CDK6. ${ }^{31}$ Previous studies from our group and others have documented significantly reduced expression and hypermethylation of p16 in HMs and CCAs, particularly in patients who developed persistent GTN than those with spontaneous regression. ${ }^{32,33}$ Aberrant methylation of p16 associated with its loss of expression in tumor cells have also been found in other tumors, including esophageal, colon, prostate, and pancreatic carcinomas, supporting the prominent tumor suppression role of $\mathrm{p} 16 .^{31,34,35}$ The reciprocal expression pattern of PAK1 and $\mathrm{p} 16$ in GTD suggests that PAK1 is a putative upstream negative regulator of $\mathrm{p} 16$.

Besides proliferation, PAK1 can also regulates cellular polarity and motility through cytoskeletal reorganization, and hence affects cell invasion. ${ }^{5,6}$ Overexpression of PAK1 has been correlated with human breast cancer invasiveness and tumor grade. ${ }^{11}$ The present study also revealed the participation of PAK1 in the aggressive behavior of trophoblasts in HMs, CCAs, and PSTT, based 
on its overexpression and the reduced CCA cell migration and invasion after knockdown of PAK1. We also found that PAK1 may control CCA cell invasion through its regulation on the expression of VEGF and MT1-MMP. VEGF is a potent pro-angiogenic growth factor and has also been found to regulate ovarian cancer cell migration and invasion, thus essential for tumor growth and metastasis. ${ }^{36}$ We have indeed recently reported a similar inhibiting effect on VEGF expression after knockdown of PAK1 in ovarian cancers. ${ }^{9}$ The effect of PAK1 on VEGF and thus on angiogenesis is likely to be a persistent phenomenon. A recent study also documented higher VEGF expression in CCAs than in HMs. ${ }^{37}$ MT1-MMP is a pericellular collagenase and also an activator of pro-MMP2 through the formation of the MT1-MMP/proMMP-2/tissue inhibitor of metalloproteinase-2 complex, thereby controlling tumor cell invasive ability via traverse the extracellular matrix. ${ }^{38}$ This is the first report showing the expression of MT1-MMP in CCA cells. Stronger MMP-2 expression has already been reported in CCAs than in placentas and HMs. ${ }^{39}$ Our group has also documented down-regulation and promoter methylation of tissue inhibitor of metalloproteinase-3 in CCAs when compared with placentas. ${ }^{40}$ The inductive effect of PAK1 on VEGF and MT1-MMP further explains the mechanisms governing cell invasion enhancing effect of PAK1.

Unlike PAK1, PAK2 mRNA and p-PAK2 immunoreactivity showed similar expression pattern in normal first trimester placentas and GTD. It was documented that transfection of constitutively active Rac3 mutant into normal mammary epithelial cell lines significantly increases cell proliferation through PAK2. ${ }^{12}$ PAK2 also displayed both pro-apoptotic or anti-apoptotic functions. The Cterminal PAK2 fragment cleaved by caspases during apoptosis activates the JNK pathway and contributes to the morphological changes in apoptosis. ${ }^{41}$ On the other hand, full-length PAK2 has been shown to promote cell survival and suppresses cell death induced by tumor necrosis factor- $\alpha$, growth factor withdrawal, and UV light. ${ }^{42}$ Thus, PAK2 may regulate trophoblasts proliferation and apoptosis in both normal and abnormal trophoblastic tissues.

In conclusion, we have presented the first study on the expression profiles of PAK1, PAK2, and p-PAK2 in GTD and their prognostic value in predicting clinical outcome. We demonstrated that there is up-regulation of PAK 1 , but not PAK2 or p-PAK2 in HMs and CCAs. In particular, PAK1 expression was shown to associate with the development of aggressive GTN and metastasis of HMs. Furthermore, the involvement of PAK1 in the pathogenesis and clinical progress of GTD is likely to act through the regulation of cell proliferation, migration, and invasion. Although most GTDs are highly responsive to chemotherapy, chemoresistant cases especially in high-risk metastatic diseases do exist, causing problems in management despite combined chemotherapy, surgery, and radiation. ${ }^{43,44}$ Therefore, identifying novel therapeutic targets for GTDs especially those with metastatic disease is important. A recent study has identified fatty acid synthase as a potential therapeutic target for GTD via its inhibitor C93. ${ }^{45}$ In view of the fact that kinase inhibitors for the PAK family are being developed, ${ }^{13,14}$ our present findings may provide new insight into PAK1 as a potential therapeutic target in GTD.

\section{References}

1. Paradinas FJ, Elston CW: Gestational trophoblastic disease. Edited by H Fox, M Wells. Edinburgh, Churchill Livingstone, 2003, pp $1359-1430$

2. Cheung AN: Pathology of gestational trophoblastic diseases. Best Pract Res Clin Obstet Gynaecol 2003, 17:849-868

3. Shih le M: Gestational trophoblastic neoplasia-pathogenesis and potential therapeutic targets. Lancet Oncol 2007, 8:642-650

4. Manser E, Leung T, Salihuddin H, Zhao ZS, Lim L: A brain serine/ threonine protein kinase activated by Cdc42 and Rac1. Nature 1994 367:40-46

5. Bokoch GM: Biology of the p21-activated kinases. Annu Rev Biochem 2003, 72:743-781

6. Kumar R, Gururaj AE, Barnes CJ: p21-activated kinases in cancer. Nat Rev Cancer 2006, 6:459-471

7. Zhao ZS, Manser E, Lim L: Interaction between PAK and nck: a template for Nck targets and role of PAK autophosphorylation. Mol Cell Biol 2000, 20:3906-3917

8. Zhou GL, Zhuo Y, King CC, Fryer BH, Bokoch GM, Field J: Akt phosphorylation of serine 21 on Pak1 modulates Nck binding and cell migration. Mol Cell Biol 2003, 23:8058-8069

9. Siu MK, Wong ES, Chan HY, Kong DS, Woo NW, Tam KF, Ngan HY, Chan QK, Chan DC, Chan KW, Cheung AN: Differential expression and phosphorylation of Pak1 and Pak2 in ovarian cancer: effects on prognosis and cell invasion. Int J Cancer 2009 127:21-31

10. Carter JH, Douglass LE, Deddens JA, Colligan BM, Bhatt TR, Pemberton JO, Konicek S, Hom J, Marshall M, Graff JR: Pak-1 expression increases with progression of colorectal carcinomas to metastasis. Clin Cancer Res 2004, 10:3448-3456

11. Vadlamudi RK, Adam L, Wang RA, Mandal M, Nguyen D, Sahin A, Chernoff J, Hung MC, Kumar R: Regulatable expression of p21activated kinase-1 promotes anchorage-independent growth and abnormal organization of mitotic spindles in human epithelial breast cancer cells. J Biol Chem 2000, 275:36238-36244

12. Mira JP, Benard V, Groffen J, Sanders LC, Knaus UG: Endogenous, hyperactive Rac3 controls proliferation of breast cancer cells by a p21-activated kinase-dependent pathway. Proc Natl Acad Sci USA 2000, 97:185-189

13. Deacon SW, Beeser A, Fukui JA, Rennefahrt UE, Myers C, Chernoff J, Peterson JR: An isoform-selective, small-molecule inhibitor targets the autoregulatory mechanism of p21-activated kinase. Chem Biol 2008, 15:322-331

14. Eswaran J, Soundararajan M, Kumar R, Knapp S: UnPAKing the class differences among p21-activated kinases. Trends Biochem Sci 2008, 33:394-403

15. Ngan HY: The practicability of FIGO 2000 staging for gestational trophoblastic neoplasia. Int J Gynecol Cancer 2004, 14:202-205

16. Cheung AN, Ngan HY, Collins RJ, Wong YL: Assessment of cell proliferation in hydatidiform mole using monoclonal antibody MIB1 to Ki-67 antigen. J Clin Pathol 1994, 47:601-604

17. Xue WC, Khoo US, Ngan HY, Chan KY, Chiu PM, Tsao SW, Cheung AN: Minichromosome maintenance protein 7 expression in gestational trophoblastic disease: correlation with Ki67, PCNA, and clinicopathological parameters. Histopathology 2003, 43:485-490

18. Cheung AN, Khoo US, Lai CY, Chan KY, Xue WC, Cheng DK, Chiu PM, Tsao SW, Ngan HY: Metastatic trophoblastic disease after an initial diagnosis of partial hydatidiform mole: genotyping and chromosome in situ hybridization analysis. Cancer 2004, 100:1411-1417

19. Lai CY, Chan KY, Khoo US, Ngan HY, Xue WC, Chiu PM, Tsao SW, Cheung AN: Analysis of gestational trophoblastic disease by genotyping and chromosome in situ hybridization. Mod Pathol 2004, 17:40-48

20. Feng HC, Choy MY, Deng W, Wong HL, Lau WM, Cheung AN, Ngan HY, Tsao SW: Establishment and characterization of a human firsttrimester extravillous trophoblast cell line (TEV-1). J Soc Gynecol Investig 2005, 12:e21-e32

21. Chan HY, Siu MK, Zhang HJ, Wong ES, Ngan HY, Chan KY, Cheung 
AN: Activated Stat3 expression in gestational trophoblastic disease: correlation with clinicopathological parameters and apoptotic indices. Histopathology 2008, 53:139-146

22. Siu MK, Wong ES, Chan HY, Ngan HY, Chan KY, Cheung AN: Overexpression of NANOG in gestational trophoblastic diseases: effect on apoptosis, cell invasion, and clinical outcome. Am J Pathol 2008, 173:1165-1172

23. Zhang HJ, Xue WC, Siu MK, Liao XY, Ngan HY, Cheung AN: P63 expression in gestational trophoblastic disease: correlation with proliferation and apoptotic dynamics. Int J Gynecol Pathol 2009, 28:172-178

24. Au CW, Siu MK, Liao X, Wong ES, Ngan HY, Tam KF, Chan DC, Chan QK, Cheung AN: Tyrosine kinase $B$ receptor and BDNF expression in ovarian cancers-Effect on cell migration, angiogenesis and clinical outcome. Cancer Lett 2009, 281:151-161

25. Aoki H, Yokoyama T, Fujiwara K, Tari AM, Sawaya R, Suki D, Hess KR, Aldape KD, Kondo S, Kumar R, Kondo Y: Phosphorylated Pak1 level in the cytoplasm correlates with shorter survival time in patients with glioblastoma. Clin Cancer Res 2007, 13:6603-6609

26. Bagheri-Yarmand R, Mandal M, Taludker AH, Wang RA, Vadlamudi RK, Kung HJ, Kumar R: Etk/Bmx tyrosine kinase activates Pak1 and regulates tumorigenicity of breast cancer cells. J Biol Chem 2001, 276:29403-29409

27. Schraml P, Schwerdtfeger G, Burkhalter F, Raggi A, Schmidt D, Ruffalo T, King W, Wilber K, Mihatsch MJ, Moch H: Combined array comparative genomic hybridization and tissue microarray analysis suggest PAK1 at 11q13.5-q14 as a critical oncogene target in ovarian carcinoma. Am J Pathol 2003, 163:985-992

28. Ching YP, Leong VY, Lee MF, Xu HT, Jin DY, Ng IO: P21-activated protein kinase is overexpressed in hepatocellular carcinoma and enhances cancer metastasis involving c-Jun $\mathrm{NH} 2$-terminal kinase activation and paxillin phosphorylation. Cancer Res 2007, 67:36013608

29. Thiel DA, Reeder MK, Pfaff A, Coleman TR, Sells MA, Chernoff J: Cell cycle-regulated phosphorylation of p21-activated kinase 1. Curr Biol 2002, 12:1227-1232

30. Wang RA, Zhang H, Balasenthil S, Medina D, Kumar R: PAK1 hyperactivation is sufficient for mammary gland tumor formation. Oncogene 2006, 25:2931-2936

31. Sherr CJ: The INK4a/ARF network in tumour suppression. Nat Rev Mol Cell Biol 2001, 2:731-737

32. Fu C, Zhang Q, Lu F, Zhang Z, Hu Y, Lin L: [The expressions of $p 16$. CDK4 and PCNA proteins in trophoblastic tumors]. Hunan Yi Ke Da Xue Xue Bao 1998, 23:17-20

33. Xue WC, Chan KY, Feng HC, Chiu PM, Ngan HY, Tsao SW, Cheung AN: Promoter hypermethylation of multiple genes in hydatidiform mole and choriocarcinoma. J Mol Diagn 2004, 6:326-334
34. Konishi N, Nakamura M, Kishi M, Nishimine M, Ishida E, Shimada K: Heterogeneous methylation and deletion patterns of the INK4a/ARF locus within prostate carcinomas. Am J Pathol 2002, 160:1207-1214

35. Fukushima N, Sato N, Ueki T, Rosty C, Walter KM, Wilentz RE, Yeo CJ, Hruban RH, Goggins M: Aberrant methylation of preproenkephalin and p16 genes in pancreatic intraepithelial neoplasia and pancreatic ductal adenocarcinoma. Am J Pathol 2002, 160:1573-1581

36. Wang FQ, So J, Reierstad S, Fishman DA: Vascular endothelial growth factor-regulated ovarian cancer invasion and migration involves expression and activation of matrix metalloproteinases. Int $J$ Cancer 2006, 118:879-888

37. Bolat F, Haberal N, Tunali N, Aslan E, Bal N, Tuncer I: Expression of vascular endothelial growth factor (VEGF), hypoxia inducible factor 1 alpha (HIF- $1 \alpha)$, and transforming growth factors $\beta 1$ (TGF $\beta 1$ ) and $\beta 3$ (TGF $\beta 3$ ) in gestational trophoblastic disease, Pathol Res Pract 2010, 206:19-23

38. Sabeh F, Ota I, Holmbeck K, Birkedal-Hansen H, Soloway P, Balbin M, Lopez-Otin C, Shapiro S, Inada M, Krane S, Allen E, Chung D, Weiss SJ: Tumor cell traffic through the extracellular matrix is controlled by the membrane-anchored collagenase MT1-MMP. J Cell Biol 2004, 167:769-781

39. Vegh GL, Selcuk Tuncer Z, Fulop V, Genest DR, Mok SC, Berkowitz RS: Matrix metalloproteinases and their inhibitors in gestational trophoblastic diseases and normal placenta. Gynecol Oncol 1999, $75: 248-253$

40. Feng $\mathrm{H}$, Cheung AN, Xue WC, Wang $\mathrm{Y}$, Wang $\mathrm{X}$, Fu S, Wang Q, Ngan HY, Tsao SW: Down-regulation and promoter methylation of tissue inhibitor of metalloproteinase 3 in choriocarcinoma. Gynecol Oncol 2004, 94:375-382

41. Lee N, MacDonald H, Reinhard C, Halenbeck R, Roulston A, Shi T, Williams LT: Activation of hPAK65 by caspase cleavage induces some of the morphological and biochemical changes of apoptosis. Proc Natl Acad Sci USA 1997, 94:13642-13647

42. Jakobi R, Moertl E, Koeppel MA: p21-activated protein kinase gamma-PAK suppresses programmed cell death of BALB3T3 fibroblasts. J Biol Chem 2001, 276:16624-16634

43. Foulmann K, Guastalla JP, Caminet N, Trillet-Lenoir V, Raudrant D, Golfier F, Schott AM: What is the best protocol of single-agent methotrexate chemotherapy in nonmetastatic or low-risk metastatic gestational trophoblastic tumors? A review of the evidence. Gynecol Oncol 2006, 102:103-110

44. Lurain JR, Nejad B: Secondary chemotherapy for high-risk gestational trophoblastic neoplasia. Gynecol Oncol 2005, 97:618-623

45. Ueda SM, Mao TL, Kuhajda FP, Vasoontara C, Giuntoli RL, Bristow RE, Kurman RJ, Shih le M: Trophoblastic neoplasms express fatty acid synthase, which may be a therapeutic target via its inhibitor C93. Am J Pathol 2009, 175:2618-2624 